\section{Optimization of Removal Efficiency and Minimum Contact Time for Cadmium and Zinc Removal onto Iron-modified Zeolite in a Two-stage Batch Sorption Reactor ${ }^{*}$}

\author{
M. Ugrina, ${ }^{* *}$ N. Vukojević Medvidović, M. Trgo, and I. Nuić \\ Faculty of Chemistry and Technology, \\ University of Split, Ruđera Boškovića 35, \\ 21000 Split, Croatia
}

doi: 10.15255/CABEQ.2017.1119

Original scientific paper

Received: March 14, 2017

Accepted: November 3, 2017

In highly congested industrial sites where significant volumes of effluents have to be treated in the minimum contact time, the application of a multi-stage batch reactor is suggested. To achieve better balance between capacity utilization and cost efficiency in design optimization, a two-stage batch reactor is usually the optimal solution. Thus, in this paper, a two-stage batch sorption design approach was applied to the experimental data of cadmium and zinc uptake onto iron-modified zeolite. The optimization approach involves the application of the Vermeulen's approximation model and mass balance equation to kinetic data. A design analysis method was developed to optimize the removal efficiency and minimum total contact time by combining the time required in the two-stages, in order to achieve the maximum percentage of cadmium and zinc removal using a fixed mass of zeolite. The benefits and limitations of the two-stage design approach have been investigated and discussed.

Keywords:

two-stage batch design, iron-modified zeolite, zinc, cadmium, optimization

\section{Introduction}

The batch scale mode is very often used for heavy metal ions uptake onto different sorbent materials. Although a single-stage operation has high operating flexibility, in some cases it cannot achieve high levels of metal ion removal. Therefore, multistage operations which include small separate batches of sorbents with filtration between each stage, are more desirable in order to enhance the sorbent efficiency, minimize the total amount of the sorbent used and make the process more economic. However, the cost and performance of the product/ equipment/system and the selection of the mode for application are always the main factors influencing process efficiency. By increasing the number of stages, the capital cost increases as well as the operating costs, due to additional filtration and handling expenses. Therefore, in practical application, twostage batch reactors are usually applied. ${ }^{1-7}$ In literature, two different design approaches to two-stage batch reactors can be found. The first approach is based on the application of the operating line meth-

"Presented at the " $4^{\text {th }}$ International Symposium on Environmental Management - Towards Circular Economy (SEM2016), December 7 - 9, Zagreb, Croatia"

${ }^{* *}$ Corresponding author: Tel.: +385-21-329 451; Fax: +385-21-329461; E-mail address: mugrin@ktf-split.hr od and the Henry law or the application of the operating line method and isotherms to equilibrium data of sorption onto sorbent in order to minimise the total amount of sorbent required to achieve a specific percentage of sorbent removal. The second approach involves the application of a kinetic model and mass balance equation to kinetic sorption data onto sorbent in order to minimize the contact time required for achieving a certain percentage of sorbent removal. ${ }^{8-14}$

In this study, the two-stage batch sorption design approach was applied to the experimental data of zinc and cadmium removal onto iron-modified zeolite. The optimization approach involves the application of the Vermeulen's approximation model and mass balance equation to the kinetic data of zinc and cadmium removal onto iron-modified zeolite, as our previous investigations showed that intraparticle diffusion was the rate-limiting step. ${ }^{15}$ To our knowledge, this is the first attempt to design two-stage batch sorption based on the mass balance equation and the Vermeulen's approximation model. In order to understand better the two-stage batch sorption design optimization approach, the Vermeulen's approximation model and mass balance equation have been explained in the Theoretical background section. 


\section{Materials and methods}

\section{Sample preparation}

The natural zeolite (NZ) originated from the Zlatokop deposit, Vranjska Banja, Serbia. The sample was milled and sieved to the particle size fractions of $0.6-0.8 \mathrm{~mm}$. After rinsing and drying at $60{ }^{\circ} \mathrm{C}$, the sample was stored in a desiccator.

The iron-modified zeolite (IMZ) was prepared from NZ according to the procedure published previously. ${ }^{16}$ The natural zeolite sample was treated separately in three stages: in aqueous solutions of $\mathrm{Fe}\left(\mathrm{NO}_{3}\right)_{3} \cdot 9 \mathrm{H}_{2} \mathrm{O}$ prepared in acetate buffer at $\mathrm{pH}=$ 3.6, followed by $\mathrm{NaOH}$ and $\mathrm{NaNO}_{3}$ solutions. Both steps of the modification procedure are responsible for the enhanced metal sorption, due to the increase in the negative surface charge of the iron-modified zeolite sample which is compensated by exchangeable sodium ions.

\section{Kinetic study in the single-stage reactor}

The sorption of zinc and cadmium on IMZ was carried out by the batch method in solutions of zinc $\left(C=5.647-14.821 \mathrm{mmol} \mathrm{Zn} \mathrm{L}^{-1}\right)$ and cadmium $\left(C_{0}^{0}=6.147-14.510 \mathrm{mmol} \mathrm{Cd} \mathrm{L^{-1 }}\right)$ at a constant $\mathrm{S} / \mathrm{L}$ ratio of $10 \mathrm{~g} \mathrm{~L}^{-1}(35 \mathrm{~g} / 3.5 \mathrm{~L})$, and in the period of $24 \mathrm{~h}$. Solutions were prepared by dissolving appropriate amounts of $\mathrm{Cd}\left(\mathrm{NO}_{3}\right)_{2} \cdot 4 \mathrm{H}_{2} \mathrm{O}$ and $\mathrm{Zn}\left(\mathrm{NO}_{3}\right)_{2} \cdot 6 \mathrm{H}_{2} \mathrm{O}$ salts in ultrapure water without adjusting the initial $\mathrm{pH}$ value according to the previously published paper. ${ }^{17}$ The initial $\mathrm{pH}$ was in the range of $4.62-5.29$ for zinc solutions and 5.30 6.79 for cadmium solutions. At defined time intervals, portions of $10 \mathrm{~cm}^{3}$ of the suspension were taken and filtered. The total sampling volume was less than $6 \%$ of the total solution volume. The concentrations of remaining zinc and cadmium ions were determined by means of an ion chromatograph Metrohm 761 Compact IC, with a conductivity detector. ${ }^{15}$

\section{Kinetic study in the two-stage reactor}

The sorption of zinc and cadmium on IMZ in two-stage reactor was conducted in order to confirm the predictions obtained by optimizing the results from single-stage by using Vermeulen's approximation model. The experiment was performed at a constant $\mathrm{S} / \mathrm{L}$ ratio of $10 \mathrm{~g} \mathrm{~L}^{-1}$, at room temperature and in two steps. In the first step, $1.5000 \mathrm{~g}$ of iron-modified zeolite was mixed with $150 \mathrm{~mL}$ of zinc $\left(C_{\mathrm{o}}=1.00-4.70 \mathrm{mmol} \mathrm{Zn} \mathrm{L} \mathrm{L}^{-1}\right)$ or cadmium

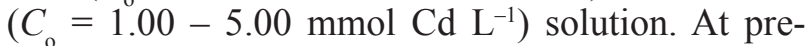
cisely defined time intervals obtained by predicting the binding of zinc (Table 3 ) and cadmium (Table 4) in two-stage reactor using Eq. (10) and (11), the experiment was terminated. The iron-modified zeolite was separated from the aqueous phase by filtration and one part of supernatant was analysed on remaining concentration of zinc and cadmium. In the second step, the rest of $100 \mathrm{~mL}$ of supernatant of zinc or cadmium was mixed with $1.0000 \mathrm{~g}$ of iron-modified zeolite in the time obtained by predicting (Table 3 and 4). After that, the concentrations of remaining zinc and cadmium ions were determined and the removal efficiency in both stages calculated.

\section{Design of a two-stage batch reactor}

A two-stage batch reactor has been designed by placing the stages in series, the wastewater first passes through stage 1 and then through stage 2 . Fresh sorbent is added in both stages. For the removal of metal ions, the minimum total contact time is achieved by combining the time required in the two stages, and this value has been optimized for maximal removal percentage of metal ions from both stages. Fig. 1 shows the schematic diagram of the two-stage batch sorption process. $7,13,14,18-20$

To design a two-stage batch sorption system, the concentration of metal ions was reduced from $C_{\text {o }}$ to $C_{1}$ in stage 1 , and from $C_{1}$ to $C_{2}$ in stage 2 . At

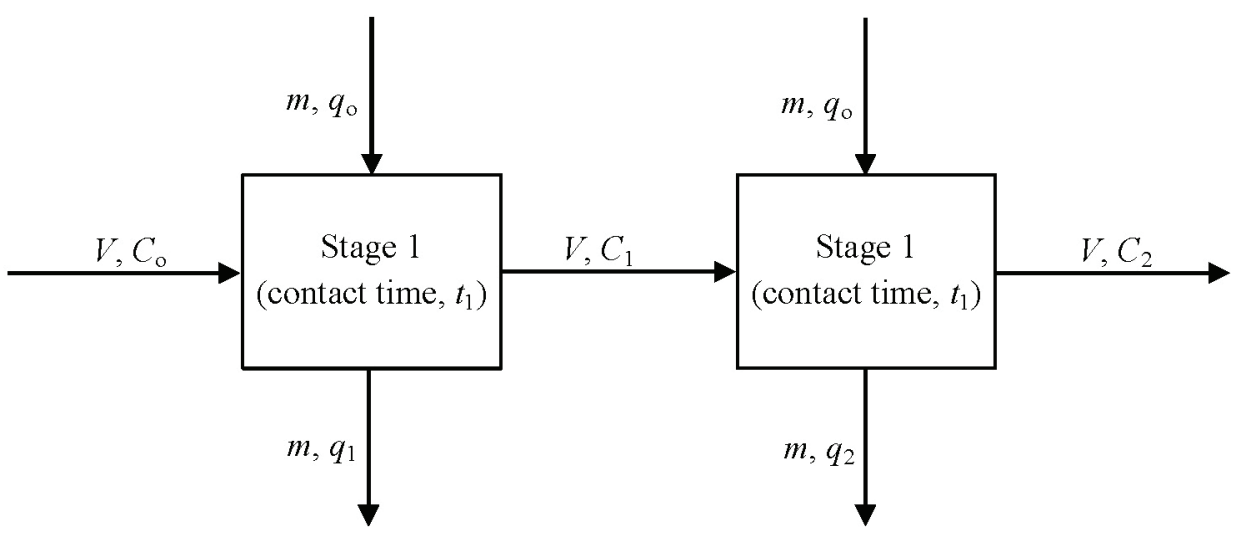

Fig. 1 - Schematic diagram of the two-stage batch sorption process 
the initial time, $t=0$, the amount of sorbent was added with the solid-phase concentration, $q_{0}$ equal to zero (as fresh sorbent is added), and finally the metal concentration on the sorbent increased to $q_{\mathrm{t}}$. This can be represented in the form of the mass balance equation for the two-stage reactor: ${ }^{1-3,8-11}$

$$
V \cdot\left(C_{\mathrm{o}}-C_{2}\right)=m \cdot\left(q_{\mathrm{t}}-q_{\mathrm{o}}\right)
$$

where $V$ is the volume of the solution (L), $C_{0}, C_{1}$ and $C_{2}$ are concentrations of metal ions in the solution initially, after stage 1 and stage $2\left(\mathrm{mmol} \mathrm{L}^{-1}\right)$, $q_{\mathrm{o}}$ and $q_{\mathrm{t}}$ are solid-phase metal ions concentrations initially and at time $t\left(\mathrm{mmol} \mathrm{g}^{-1}\right)$, and $m$ is the mass of the sorbent $(\mathrm{g})$.

The sorption kinetic study in a previous paper has shown that the intraparticle diffusion is the rate-limiting step, and that the best fit of the experimental data is observed with the Vermeulen's approximation model, given by the equation: ${ }^{15,21}$

$$
q_{\mathrm{t}}=q_{\mathrm{e}} \cdot\left[1-e^{\left(\frac{-D_{\mathrm{i}} \cdot \pi^{2} \cdot t}{r_{\mathrm{p}}^{2}}\right)}\right]^{1 / 2}
$$

where $q$ is the solid-phase metal ions concentration at equilibrium $\left(\mathrm{mmol} \mathrm{g}^{-1}\right), r_{\mathrm{p}}$ is the particle radius $(\mathrm{cm})$, and $D_{\mathrm{i}}$ is the intraparticle diffusion coefficient of metal ions $\left(\mathrm{cm}^{2} \mathrm{~min}^{-1}\right)$.

Upon insertion of Eq. (2) into the mass balance Eq. (1) and if the sorbent was initially free, the following equation is obtained:

$$
C_{\mathrm{o}}-C_{2}=\frac{m}{V} \cdot q_{\mathrm{e}} \cdot\left[1-e^{\left(\frac{-D_{\mathrm{i}} \cdot \pi^{2} \cdot t}{r_{\mathrm{p}}^{2}}\right)}\right]^{1 / 2}
$$

The total metal ions removal for the two-stage batch reactor was calculated as follows:

$$
\begin{aligned}
& \left(C_{\mathrm{o}}-C_{2}\right)=\left(C_{\mathrm{o}}-C_{1}\right)-\left(C_{1}-C_{2}\right)= \\
& =\frac{m}{V} \cdot q_{\mathrm{e}, 1} \cdot\left[1-e^{\left(\frac{-D_{\mathrm{i}, 1} \cdot \pi^{2} \cdot t_{1}}{r_{\mathrm{p}}^{2}}\right)}\right]^{1 / 2}+ \\
& +\frac{m}{V} \cdot q_{\mathrm{e}, 2} \cdot\left[1-e^{\left(\frac{-D_{\mathrm{i}, 2} \cdot \pi^{2} \cdot t_{2}}{r_{\mathrm{p}}^{2}}\right)}\right]^{1 / 2}
\end{aligned}
$$

where:

$q_{\mathrm{e}, 1}, q_{\mathrm{e}, 2}$ are the solid-phase metal ions concentration in stages 1 and $2\left(\mathrm{mmol} \mathrm{g}^{-1}\right)$,

$D_{\mathrm{i}, 1,1} D_{\mathrm{i}, 2}$ are the intraparticle diffusion coefficients of metal ions in stages 1 and $2\left(\mathrm{~cm}^{2} \mathrm{~min}^{-1}\right)$,

$t_{1}, t_{2}$ are the minimum contact times in stages 1 and 2 (min).
The overall removal percentage of metal ion onto the sorbent in two stages, $R$ represents the sum of values of removal percentages obtained in each stage, $R_{1}$ and $R_{2}$, is calculated by using the following equations: ${ }^{4-7,14,19,20}$

$$
R=\frac{100 \cdot\left(C_{\mathrm{o}}-C_{2}\right)}{C_{\mathrm{o}}}=\frac{100 \cdot m}{V \cdot C_{\mathrm{o}}} \cdot\left(q_{\mathrm{t}, 1}+q_{\mathrm{t}, 2}\right)
$$

$R=R_{1}+R_{2}=\frac{100 \cdot\left[\left(C_{\mathrm{o}}-C_{1}\right)-\left(C_{1}-C_{2}\right)\right]}{C_{\mathrm{o}}}=$

$$
=\frac{100 \cdot m}{V \cdot C_{\mathrm{o}}} \cdot\left\{q_{\mathrm{e}, 1} \cdot\left[1-e^{\left(\frac{-D_{\mathrm{i}, 1} \cdot \pi^{2} \cdot t_{1}}{r_{\mathrm{p}}^{2}}\right)}\right]^{1 / 2}+q_{\mathrm{e}, 2} \cdot\left[1-e^{\left(\frac{-D_{\mathrm{i}, 2} \cdot \pi^{2} \cdot t_{2}}{r_{\mathrm{p}}^{2}}\right)}\right]^{1 / 2}\right\}
$$

where $q_{\mathrm{e}}$ and $D_{\mathrm{i}}$ are expressed as a function of $C_{\mathrm{o}}$ for metal ion removal onto the sorbent as follows:

$$
\begin{aligned}
q_{\mathrm{e}} & =a \cdot C_{\mathrm{o}}^{b} \\
D_{\mathrm{i}} & =x \cdot C_{\mathrm{o}}^{y}
\end{aligned}
$$

Constants $a, b, x$ and $y$ are determined by plotting $q_{\mathrm{e}}$ and $D_{\mathrm{i}}$ in relation to $C_{\mathrm{o}}$ (the initial metal ion concentration).

The substitution of values of $q_{\mathrm{e}}$ and $D_{\mathrm{i}}$ from Eqs. (7) and (8) into Eq. (6) yields:

$R=R_{1}+R_{2}=\frac{100 \cdot m}{V \cdot C_{\mathrm{o}}}$.

$$
\left\{a \cdot C_{\mathrm{o}}^{b} \cdot\left[1-e^{\left(\frac{-x \cdot C_{0}^{y} \cdot \pi^{2} \cdot t_{1}}{r_{\mathrm{p}}^{2}}\right)}\right]^{1 / 2}+a \cdot C_{1}^{b} \cdot\left[1-e^{\left(\frac{-x \cdot C_{1}^{y} \cdot \pi^{2} \cdot t_{2}}{r_{\mathrm{p}}^{2}}\right)}\right]^{1 / 2}\right\}
$$

Equation (9) can be used to calculate the contact time in the two-stage batch reactor for heavy metal removal for the given initial concentration and desired removal efficiency.

In this paper, optimization was performed in order to increase the overall removal percentage, $R$, and to minimize the total contact time, $T$. To optimize the overall removal percentage through both stages, contact times $t_{1}$ and $t_{2}$ were assumed to be equal $\left(t_{1}=t_{2}\right)$ and divided into 25-minute intervals ranging from 0 to 500 minutes, and each interval was marked by a system number; $N=1,2,3, \ldots 20$ $\left(t_{1}=t_{2}=25 \mathrm{~N}\right)$. To optimize the minimum total contact time, $T$, through both stages, the contact time $t_{1}$ was set by dividing it into 10 -minute intervals ranging from 10 to 500 minutes, and each interval was marked by a system number; $N=1,2,3, \ldots 50$. Thus, the contact time in stage 1 can be described by:

$$
t_{1}=10+(N-1) \cdot 10
$$

where $N$ is a system number. 
The total contact time, $T$, required for achieving a fixed percentage of metal ion removal was evaluated using the two-stage reactor optimization. For an evaluated value of the total contact time, $T$, the contact time in stage $2, t_{2}$ is calculated, according to:

$$
t_{2}=-\frac{r_{\mathrm{p}}^{2}}{x \cdot C_{1}^{y} \cdot \pi^{2}} \cdot \ln \left\{1-\left[\frac{\left(R_{1}+R_{2}\right) \cdot V \cdot C_{\mathrm{o}}-100 \cdot m \cdot a \cdot C_{\mathrm{o}}^{b} \cdot\left(1-e^{-\frac{x \cdot C_{\mathrm{o}}^{y} \cdot \pi^{2} \cdot \cdot_{1}}{r_{\mathrm{p}}^{2}}}\right)}{100 \cdot m \cdot a \cdot C_{1}^{b}}\right]\right\}^{2}
$$

Then, the total contact time, $T$ is:

$$
T=t_{1}+t_{2}
$$

The insertion of Eq. (10) into Eq. (12) yields:

$$
T=10+(N-1) \cdot 10 \min +t_{2}
$$

\section{Results and discussion}

\section{Model application for calculation of diffusion mass transfer parameters}

The kinetics of zinc and cadmium uptake by the single-stage batch method presented in Fig. 2 shows two kinetic stages, a fast uptake up to 240 min, followed by a slow uptake until the equilibration is reached, around 500 minutes. The quantities of zinc and cadmium removed per gram of IMZ are in similar range, $0.297-0.358 \mathrm{mmol} \mathrm{Zn} \mathrm{g}^{-1}$ and $0.300-0.325 \mathrm{mmol} \mathrm{Cd} \mathrm{g}^{-1}$ of IMZ. ${ }^{15}$

The removal efficiency of zinc and cadmium uptake per gram of IMZ vs. time is presented in Fig. 3 . It can be observed for both metal ions that, with the increasing initial concentration, the removal efficiency decreases, resulting in a higher remaining concentration after sorption, which does not meet the legal regulations. One of the solutions for achieving higher efficiency is the application of a two or multistage sorption process. In the design of a two-stage reactor, the optimization of contact time in the sorption process is a crucial parameter for practical application since a greater number of batch stages of wastewater can be conducted per day, which reduces the size of equipment and the capital cost. $^{2-4}$ The two-stage batch reactor for zinc and cadmium removal onto IMZ was designed by using equations (1)-(13). For that purpose, the parameters of $q_{\mathrm{e}}$ and $D_{\mathrm{i}}$ were calculated from the application of the Vermeulen's approximation and given in Table 1 .

It is evident from Table 1 that parameter $q_{\mathrm{e}}$ is concentration dependent. However, the values of $D_{\mathrm{i}}$ have the same order of magnitude, indicating that the diffusion coefficient is not concentration dependent, which is in agreement with the assumption of the Vermeulen's approximation. In the model opti-
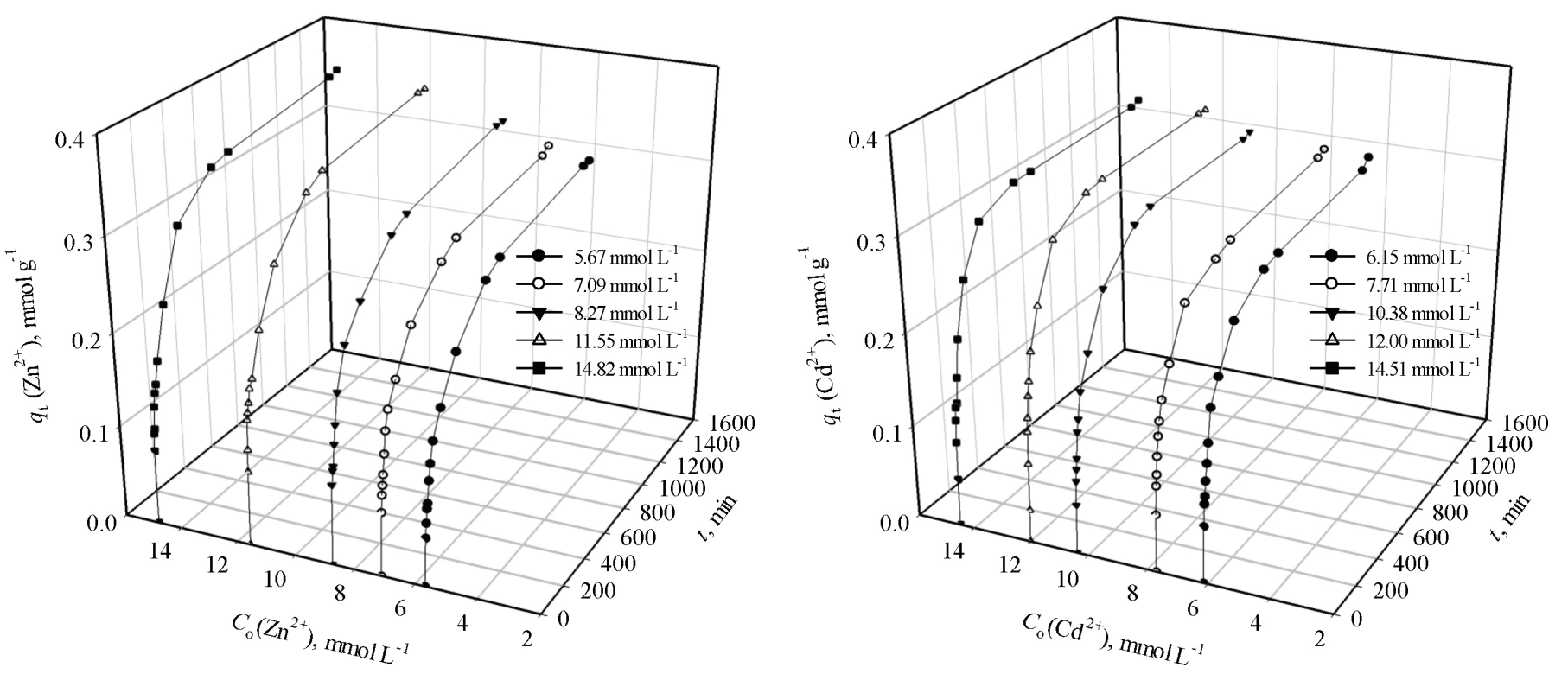

Fig. 2 - Amount of zinc and cadmium uptake per gram of IMZ vs. time and initial concentration 

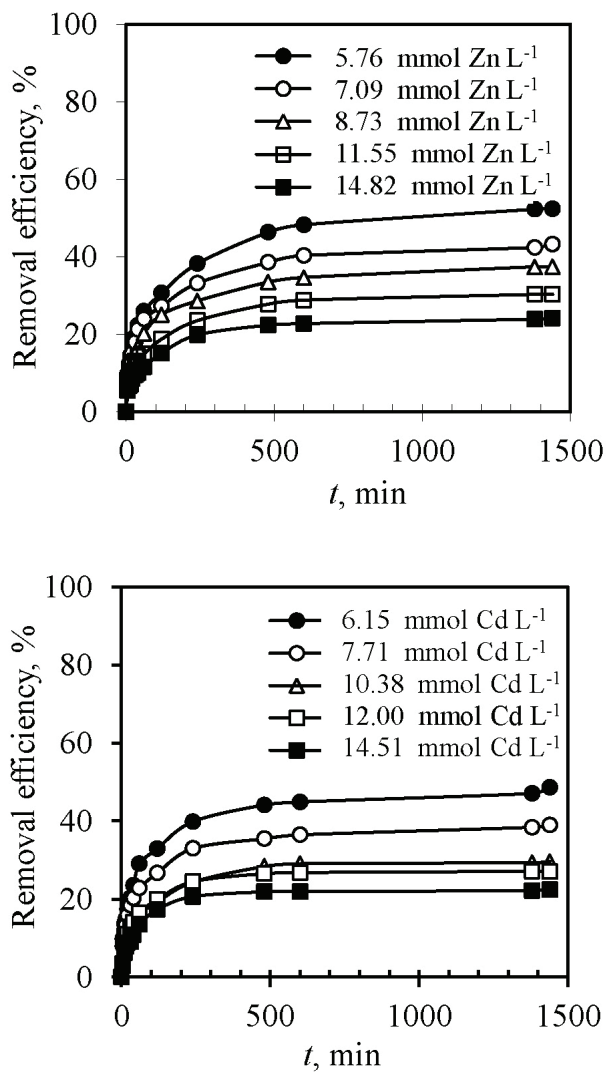

Fig. 3 - Removal efficiency of zinc and cadmium uptake per gram of IZM vs. time

mization approach, a wide range of concentrations is tested, and the parameter, $q_{\mathrm{e}}$ and $D_{\mathrm{i}}$ are expressed as a function of $C_{0}$ and the obtained relations are listed in Table 2.
Table 1 -Model parameters calculated from the Vermeulen's approximation

\begin{tabular}{|c|c|c|c|c|}
\hline $\begin{array}{c}C_{\mathrm{o}} \\
\mathrm{mmol} \mathrm{L^{-1 }}\end{array}$ & $\begin{array}{c}q_{\mathrm{e}, \exp } \\
\mathrm{mmol} \mathrm{L}^{-1}\end{array}$ & $\begin{array}{c}q_{\mathrm{e}} \\
\mathrm{mmol} \mathrm{g}^{-1}\end{array}$ & $\begin{array}{c}D_{\mathrm{i}} \cdot 10^{7} \\
\mathrm{~cm}^{2} \mathrm{~min}^{-1}\end{array}$ & $R^{2}$ \\
\hline \multicolumn{5}{|c|}{$\mathrm{Zn}$} \\
\hline 5.67 & 0.297 & 0.289 & 5.625 & 0.994 \\
\hline 7.09 & 0.307 & 0.291 & 5.854 & 0.989 \\
\hline 8.73 & 0.329 & 0.314 & 6.109 & 0.990 \\
\hline 11.55 & 0.350 & 0.341 & 6.284 & 0.989 \\
\hline 14.82 & 0.358 & 0.350 & 6.537 & 0.993 \\
\hline \multicolumn{5}{|c|}{$\mathrm{Cd}$} \\
\hline 6.15 & 0.299 & 0.289 & 7.595 & 0.994 \\
\hline 7.71 & 0.300 & 0.301 & 7.880 & 0.991 \\
\hline 10.38 & 0.307 & 0.307 & 8.281 & 0.996 \\
\hline 12.00 & 0.332 & 0.323 & 8.409 & 0.995 \\
\hline 14.51 & 0.325 & 0.333 & 8.834 & 0.996 \\
\hline
\end{tabular}

Table 2 -Relation $q_{e}$ and $D_{i}$ as a function of $C_{o}$ for metal ion removal onto IMZ

\begin{tabular}{c|c|c|c|c}
\hline & $q_{\mathrm{e}}=a \cdot C_{\mathrm{o}}^{b}$ & $R^{2}$ & $D_{\mathrm{i}}=x \cdot C_{\mathrm{o}}^{y}$ & $R^{2}$ \\
\hline $\mathrm{Zn}$ & $q_{\mathrm{e}}=0.1925 \cdot C_{\mathrm{o}}^{0.2251}$ & 0.951 & $D_{\mathrm{i}}=4.3348 \cdot 10^{-7} \cdot C_{\mathrm{o}}^{0.1533}$ & 0.988 \\
$\mathrm{Cd}$ & $q_{\mathrm{e}}=0.2156 \cdot C_{\mathrm{o}}^{0.1601}$ & 0.954 & $D_{\mathrm{i}}=5.5715 \cdot 10^{-7} \cdot C_{\mathrm{o}}^{0.1695}$ & 0.989 \\
\hline
\end{tabular}

By inserting the parameters from Table 2 into Eq. (9), the mathematical models for calculation of the overall removal percentage are obtained for our systems, given by:

for zinc:

$$
R=\frac{100 \cdot m}{V \cdot C_{\mathrm{o}}} \cdot 0.1925 \cdot\left\{C_{\mathrm{o}}^{0.2251} \cdot\left[1-e^{\left(\frac{-4.3348 \cdot 10^{-7} \cdot C_{0}^{0.1533} \cdot \pi^{2} \cdot t_{1}}{r_{\mathrm{p}}^{2}}\right)}\right]^{1 / 2}+C_{1}^{0.2251} \cdot\left[1-e^{\left(\frac{-4.3348 \cdot 10^{-7} \cdot C_{C_{\mathrm{p}}^{0.1533} \cdot \pi^{2} \cdot t_{2}}^{r_{\mathrm{p}}^{2}}}{r^{2}}\right]^{1 / 2}}\right\}\right.
$$

for cadmium:

$$
R=\frac{100 \cdot m}{V \cdot C_{\mathrm{o}}} \cdot 0.2156 \cdot\left\{C_{\mathrm{o}}^{0.1601} \cdot\left[1-e^{\left(\frac{-5.5715 \cdot 10^{-7} \cdot C_{0}^{0.1695} \cdot \pi^{2} \cdot t_{1}}{r_{\mathrm{p}}^{2}}\right)}\right]^{1 / 2}+C_{1}^{0.1601} \cdot\left[1-e^{\left(\frac{-5.5715 \cdot 10^{-7} \cdot C_{1}^{0.1695} \cdot \pi^{2} \cdot t_{2}}{r_{\mathrm{p}}^{2}}\right)}\right]^{1 / 2}\right\}
$$

\section{Optimization of the removal efficiency}

Based on relations (14) and (15), for two different concentrations of zinc and cadmium and system numbers ranging from 1 to 20 in which the contact time in each stage was assumed to be equal $\left(t_{1}=t_{2}=25 \mathrm{~N}\right)$, the overall removal percentage as well as the removal percentage for stages 1 and 2 were calculated and presented in Figs. 4 and 5.
It is evident that the application of the twostage reactor for the initial metal concentration of $4 \mathrm{mmol} \mathrm{L}^{-1}$ of zinc or cadmium significantly increases the overall removal percentage. In stage 1, removal of $61.81 \%$ of zinc and $65.27 \%$ of cadmium was achieved with system number 20 (which includes 500 min contact time). However, when applying the two-stage reactor, the overall removal 

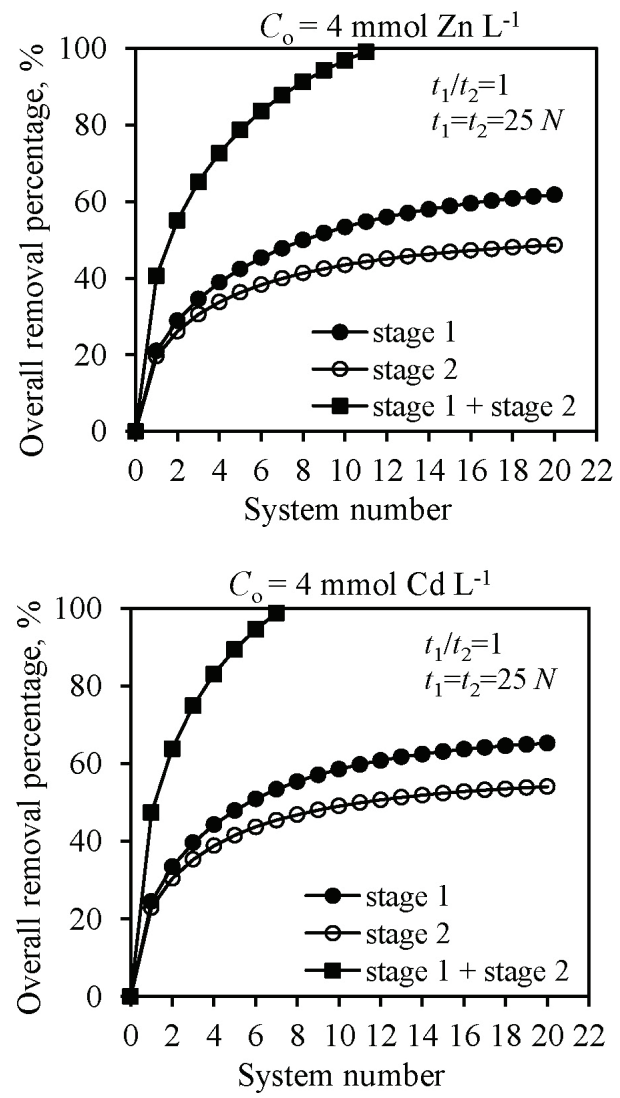

Fig. 4 - Comparison of the overall removal percentage and removal percentages in stages 1 and 2 in relation to system number for $4 \mathrm{mmol} \mathrm{L}^{-1} \mathrm{Zn}$ and $\mathrm{Cd}$

was achieved by summing the removal in each phase as follows: $99.13 \%$ of zinc removed was achieved with system number 11 (which included $275 \mathrm{~min}$ in stage 1 and $275 \mathrm{~min}$ in stage 2), while $98.80 \%$ of cadmium was removed with system number 7 (which included $175 \mathrm{~min}$ in stage 1 and $175 \mathrm{~min}$ in stage 2). A similar behaviour was observed for the initial concentration of $2 \mathrm{mmol} \mathrm{L}^{-1}$ of zinc and cadmium (Fig. 5), where in stage 1, removal of $99.88 \%$ of zinc was achieved with system number 16 (which included 400 min contact time), and $99.21 \%$ of cadmium with system number 9 (which included 225 min contact time). In this case, the almost complete removal was achieved already in stage 1, therefore, stage 2 was not required. However, the duration of the process was 400 and 225 minutes, respectively, and the application of a twostage reactor significantly increases the overall efficiency in a shorter contact time. It is evident that with the application of a two-stage reactor, zinc and cadmium removals $(>99 \%)$ were achieved with system number 3 (which included only $75 \mathrm{~min}$ in stage 1 and $75 \mathrm{~min}$ in stage 2 ). The shape of curves for stage 2 are parabolic, since the concentration of metal ions leaving stage 1 is significantly reduced, resulting in a decreased removal percentage in stage 2 .
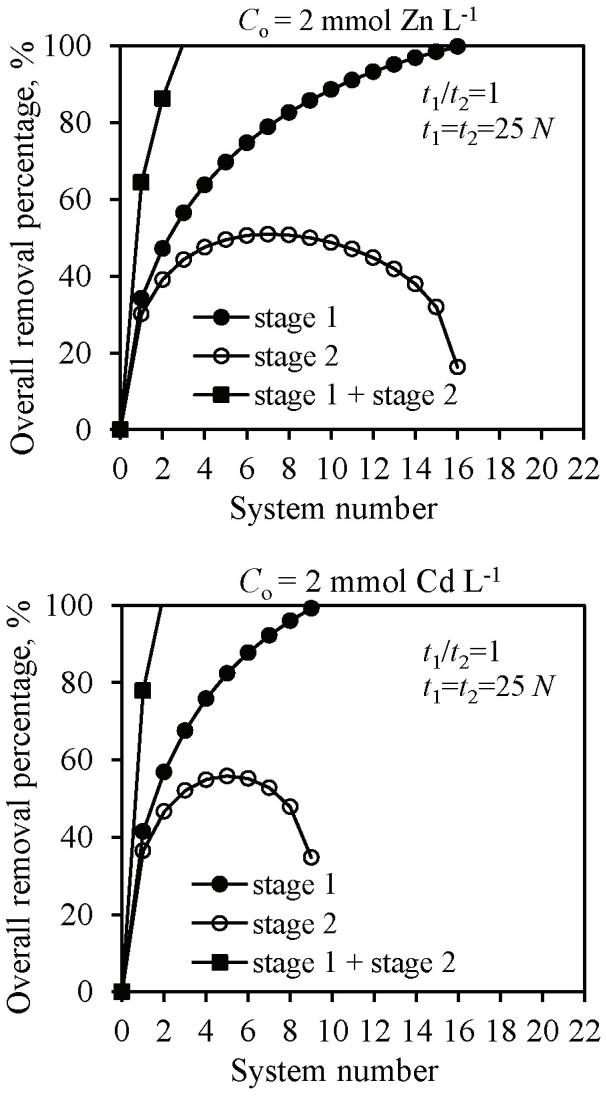

Fig. 5 - Comparison of the overall removal percentage and removal percentages in stages 1 and 2 in relation to system number for $2 \mathrm{mmol} \mathrm{L}^{-1} \mathrm{Zn}$ and $\mathrm{Cd}$

Fig. 6 presents the effect of chosen initial concentrations of zinc and cadmium on the overall removal percentage in the two-stage reactor. It is evident that for initial concentrations of both zinc and cadmium below $1 \mathrm{mmol} \mathrm{L}^{-1}$, the $100 \%$ removal efficiency is achieved in a short time and the application of a two-stage reactor is not recommended. For the concentration range from 2 to $4.7 \mathrm{mmol} \mathrm{Zn}$ $\mathrm{L}^{-1}$ and from 2 to $5 \mathrm{mmol} \mathrm{Cd} \mathrm{L}{ }^{-1}$, the $100 \%$ removal efficiency can be achieved using a two-stage reactor, while above these concentrations, the application of three or more stages is necessary to obtain higher removal efficiency.

Thus, the shaded area in Fig. 6 presents the valid range of initial concentrations for the application of a two-stage reactor. According to Hui et al..$^{9}$ for the optimal batch reactor design, the concept of a "pinch point" which defines the limiting sorption capacity position for the design and operation of the batch reactor is useful. When the initial concentration of stage 2 increases and exceeds the "pinch point" of design, the discharge concentration limit cannot be achieved and the application of a twostage reactor is not recommended. In case of zinc removal on IMZ at the defined experimental conditions, the "pinch point" is determined at the initial concentration of $4.7 \mathrm{mmol} \mathrm{L}^{-1}$ for zinc and at 

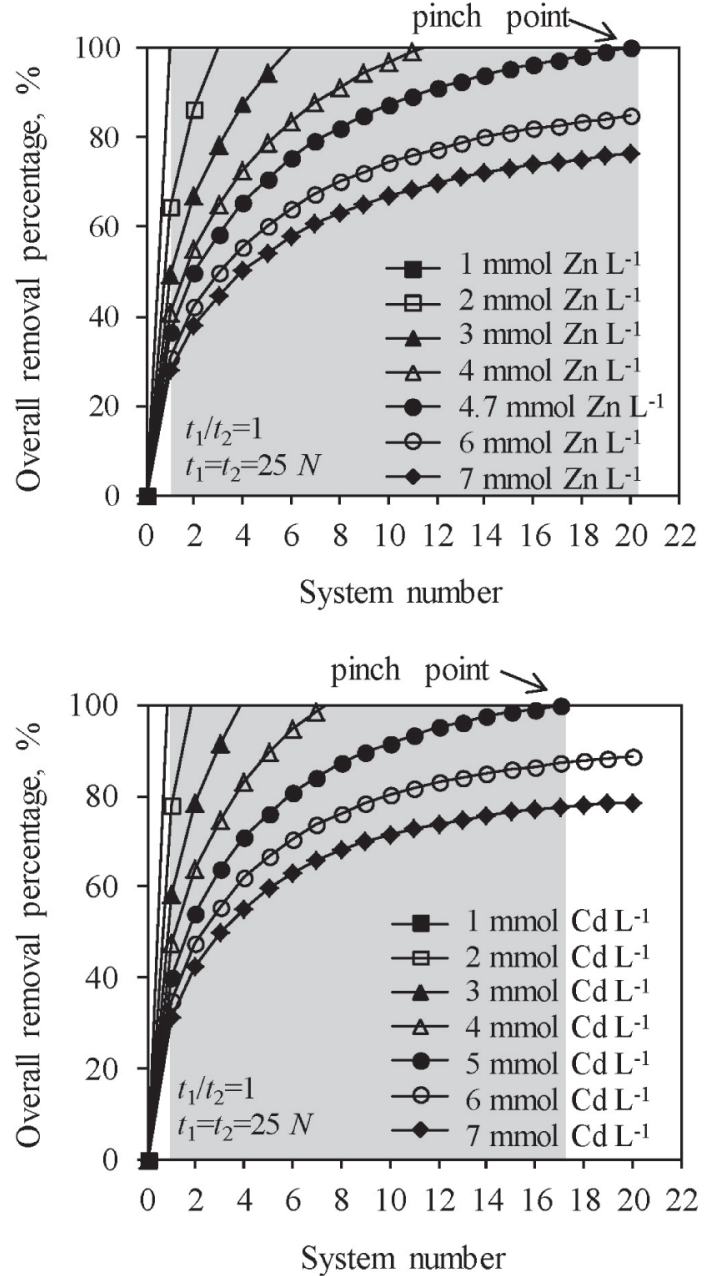

Fig. 6-Effect of the chosen initial metal concentration on the overall removal percentage of zinc and cadmium ions on IMZ in the two-stage reactor

$5 \mathrm{mmol} \mathrm{L}{ }^{-1}$ for cadmium. Thus, the effect of the initial metal concentration in designing a two-stage reactor is significant as it affects the overall removal percentage.

\section{Optimization of the minimum contact time}

To optimize the minimum total contact time, $T$, through both stages, the contact time in stage $1, t_{1}$ was set by dividing it into 10-minute intervals ranging from 10 to 500 minutes, and each interval was marked by a system number; $N=1,2,3, \ldots .50$. For the chosen initial concentration and desired removal efficiency, the total contact time was calculated using Eqs. (9)-(11). Fig. 7 presents the calculated values for the total contact time required for the initial concentration of $4 \mathrm{mmol} \mathrm{L}^{-1}$ zinc and cadmium and removal efficiency of $99 \%$.

From Fig. 7, it is clear that for $99 \%$ removal efficiency in a two-stage reactor, the contact time in stage 1 increases, and decreases in stage 2 with increasing system number. Since the total contact
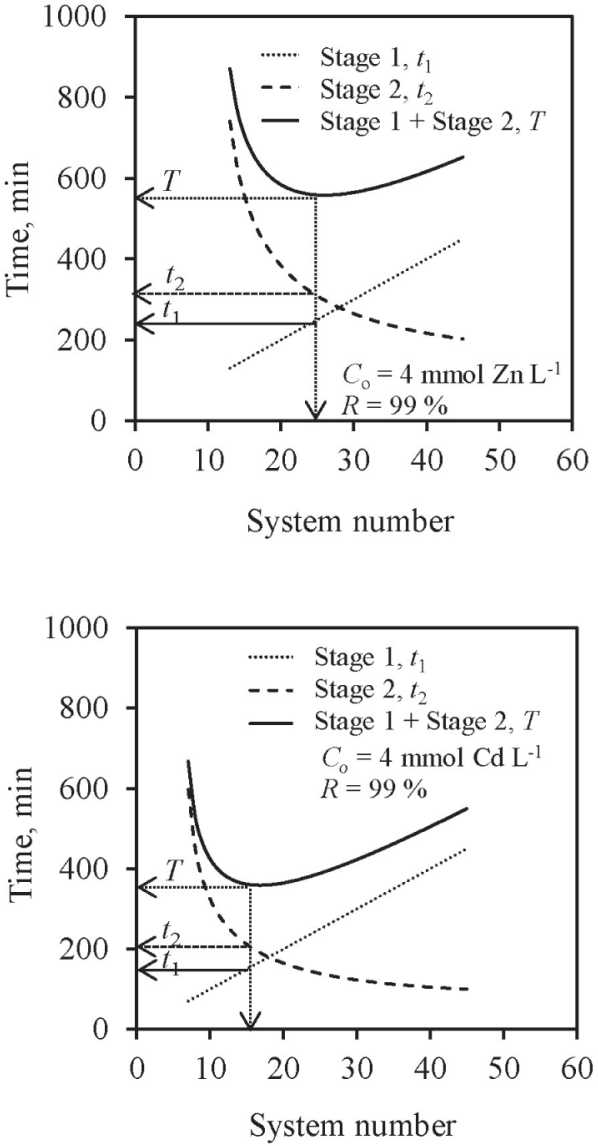

Fig. 7 - Comparison of removal time of each stage in the two-stage reactor for $99 \%$ removal efficiency of zinc and cadmium from a $4 \mathrm{mmol} L^{-1}$ solution

time, $T$, is the sum of contact times in each stage, $t_{1}$ and $t_{2}$, the purpose is to determine the optimal minimal contact time. The optimal minimal contact time represents the minimum of the summary curve (stage $1+$ stage 2 ) on the abscissa. From the intersection with curves for stage 1 and stage 2, the times in each stage of the process were determined from ordinates.

The minimum contact time for zinc is found and corresponds to system number 26 (260 $\mathrm{min}$ in stage 1 and $298 \mathrm{~min}$ in stage 2), and to system number 17 for cadmium (170 $\mathrm{min}$ in stage 1 and 189 min in stage 2).

Fig. 8 presents the minimum contact time for different removal percentages and the same initial concentration of $4 \mathrm{mmol} \mathrm{L}^{-1}$ for zinc and cadmium, while Fig. 9 shows the minimum contact time for $99 \%$ removal efficiency of zinc and cadmium for different initial concentrations.

The results show that the increase in removal percentage required increasing the minimum contact time (Fig. 8). It was found that, for certain removal percentages, higher values of the total contact time are required when the initial concentration is increased (Fig. 9). Thus, there is more than one 

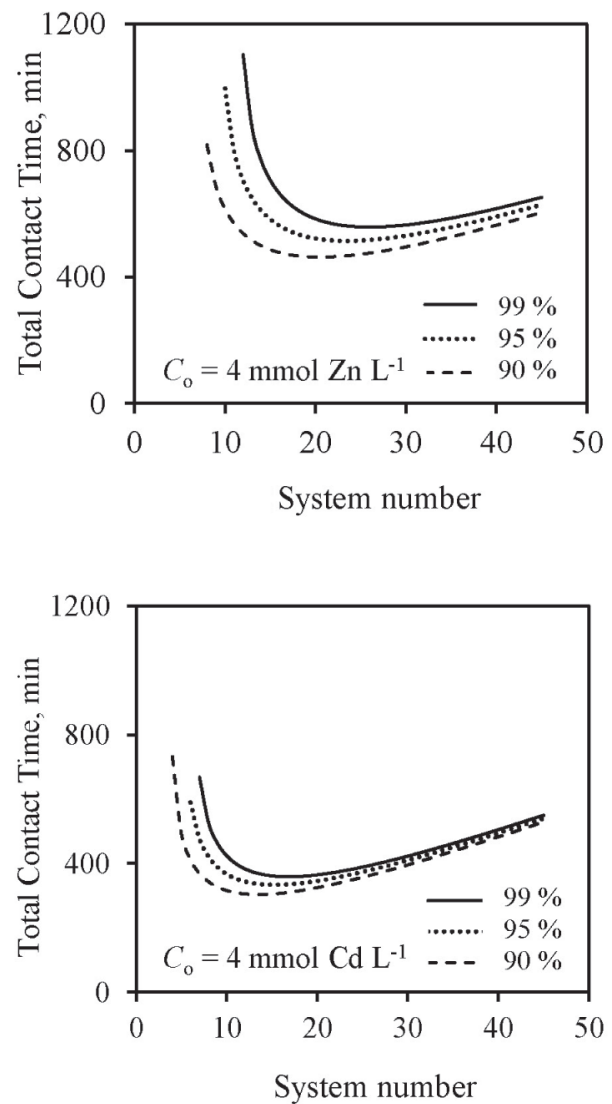

Fig. 8 - Minimum contact time for various percentage removals for the initial concentration of $4 \mathrm{mmol} \mathrm{L}^{-1}$ of zinc and cadmium

optimal solution for the total contact time for different process conditions. Tables 3 and 4 show the result of optimization to obtain the minimum total contact time, $T$, as well as the contact time in both stages to achieve $99 \%, 95 \%$ and $90 \%$ of zinc and cadmium removal on IMZ for different chosen initial concentrations. The range of initial concentrations has been selected according to the area in Fig. 6 , for which it is possible to design a two-stage reactor.

From Tables 3 and 4, it can be observed that the contact time in stage 1 is shorter than in stage 2 . This is due to a higher driving force of the sorption process in stage 1 , since the initial concentration is always higher than that in stage 2, therefore, sorption is faster. In addition, it is obvious that the minimum contact time for the same removal efficiency and the same initial concentration is approximately 1.3-1.6 times higher for zinc removal compared to that of cadmium.

\section{Experimental verification of the model application}

In order to test the calculated results from Tables 3 and 4 and validate Eqs. (14) and (15), experiments have been performed at initial concentra-

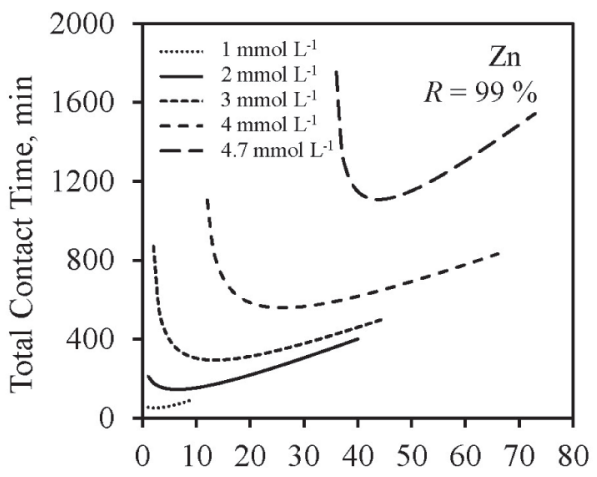

System number

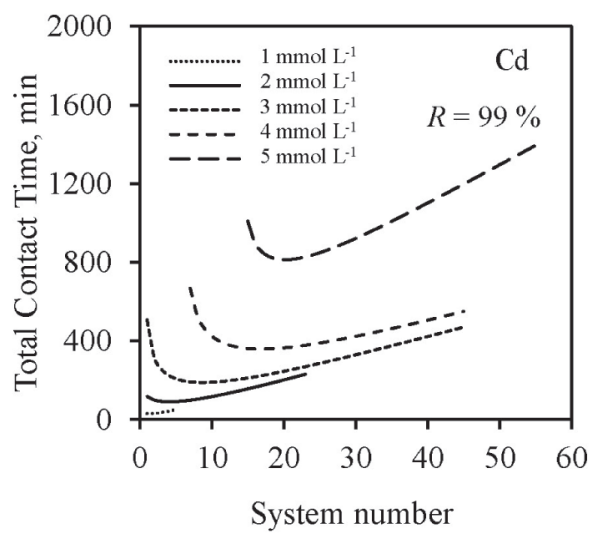

Fig. 9 - Minimum contact time to achieve $99 \%$ removal of zinc and cadmium for various initial concentrations

tions in the range $1.011-4.723 \mathrm{mmol} \mathrm{Zn} \mathrm{L}^{-1}$ and $1.005-4.997 \mathrm{mmol} \mathrm{Cd} \mathrm{L}{ }^{-1}$ with contact times $t_{1}$ and $t_{2}$ (Tables 3 and 4 ) and the desired removal efficiency. Calculated and experimentally obtained values of zinc and cadmium removal in the twostage reactor have been compared and presented in Tables 5 and 6.

The results have shown that the calculated values of removal efficiency are in good agreement with the obtained experimental values. This confirms that the application of the mass balance equation and the Vermeulen's approximation can be used for prediction of the minimum contact time for zinc and cadmium removal onto IMZ. For initial concentrations above $5 \mathrm{mmol} \mathrm{L}^{-1}$, a reactor with three or more stages should be used. However, the increasing number of stages increases the operating and capital cost. Thus, dilution of the feeding solution below $5 \mathrm{mmol} \mathrm{L}^{-1}$ or pretreatment using precipitation is suggested in order to reduce total costs. Additionally, the application of a two-stage reactor can be very useful for removal of heavy metals from a multicomponent solution which shows different affinity towards the sorbent material or using different sorbents with different selectivity towards heavy metals. 
Table 3 -Calculated minimum contact times to achieve $99 \%$, $95 \%$ and $90 \%$ zinc removal for different chosen initial concentrations

\begin{tabular}{|c|c|c|c|c|}
\hline \multirow{2}{*}{$\begin{array}{c}C_{\mathrm{o}} \\
\mathrm{mmol} \mathrm{L}^{-1}\end{array}$} & \multirow{2}{*}{$\begin{array}{l}\text { System } \\
\text { number }\end{array}$} & \multicolumn{3}{|c|}{ Minimum contact time, min } \\
\hline & & $\begin{array}{c}\text { Stage } 1 \\
t_{1}\end{array}$ & $\begin{array}{c}\text { Stage } 2 \\
t_{2}\end{array}$ & $\begin{array}{c}T \\
\left(t_{1}+t_{2}\right)\end{array}$ \\
\hline \multicolumn{5}{|c|}{ Removal percentage, $99 \%$} \\
\hline 1 & 2 & 20 & 30 & 50 \\
\hline 2 & 6 & 60 & 84 & 144 \\
\hline 3 & 13 & 130 & 163 & 293 \\
\hline 4 & 26 & 260 & 298 & 557 \\
\hline 4.7 & 52 & 520 & 587 & 1107 \\
\hline \multicolumn{5}{|c|}{ Removal percentage, $95 \%$} \\
\hline 1 & 2 & 20 & 28 & 48 \\
\hline 2 & 6 & 60 & 77 & 137 \\
\hline 3 & 12 & 120 & 156 & 276 \\
\hline 4 & 23 & 230 & 285 & 515 \\
\hline 4.7 & 44 & 440 & 506 & 946 \\
\hline \multicolumn{5}{|c|}{ Removal percentage, $90 \%$} \\
\hline 1 & 2 & 20 & 25 & 45 \\
\hline 2 & 5 & 50 & 69 & 119 \\
\hline 3 & 10 & 100 & 130 & 230 \\
\hline 4 & 20 & 200 & 263 & 463 \\
\hline 4.7 & 36 & 360 & 436 & 796 \\
\hline
\end{tabular}

Table 4 -Calculated minimum contact times to achieve $99 \%$, $95 \%$ and $90 \%$ cadmium removal for different chosen initial concentrations

\begin{tabular}{|c|c|c|c|c|}
\hline \multirow{2}{*}{$\begin{array}{c}C_{\mathrm{o}} \\
\mathrm{mmol} \mathrm{L}^{-1}\end{array}$} & \multirow{2}{*}{$\begin{array}{l}\text { System } \\
\text { number }\end{array}$} & \multicolumn{3}{|c|}{ Minimum contact time, min } \\
\hline & & $\begin{array}{c}\text { Stage } 1 \\
t_{1}\end{array}$ & $\begin{array}{c}\text { Stage } 2 \\
t_{2}\end{array}$ & $\begin{array}{c}T \\
\left(t_{1}+t_{2}\right)\end{array}$ \\
\hline \multicolumn{5}{|c|}{ Removal percentage, $99 \%$} \\
\hline 1 & 1 & 10 & 20 & 30 \\
\hline 2 & 4 & 40 & 50 & 90 \\
\hline 3 & 9 & 90 & 98 & 188 \\
\hline 4 & 17 & 170 & 189 & 359 \\
\hline 5 & 38 & 380 & 433 & 813 \\
\hline \multicolumn{5}{|c|}{ Removal percentage, $95 \%$} \\
\hline 1 & 1 & 10 & 18 & 28 \\
\hline 2 & 4 & 40 & 46 & 86 \\
\hline 3 & 8 & 80 & 98 & 178 \\
\hline 4 & 15 & 150 & 184 & 334 \\
\hline 5 & 32 & 320 & 382 & 702 \\
\hline \multicolumn{5}{|c|}{ Removal percentage, $90 \%$} \\
\hline 1 & 1 & 10 & 16 & 26 \\
\hline 2 & 3 & 30 & 50 & 80 \\
\hline 3 & 7 & 70 & 95 & 165 \\
\hline 4 & 13 & 130 & 174 & 304 \\
\hline 5 & 28 & 280 & 315 & 595 \\
\hline
\end{tabular}

Table 5 -Comparison of experimental and calculated values of removal efficiency obtained in stage 1 and stage 2 for different initial concentrations and removal percentages for zinc

\begin{tabular}{|c|c|c|c|c|c|c|c|}
\hline \multirow{2}{*}{$\begin{array}{c}\begin{array}{c}C_{\mathrm{o}} \\
\mathrm{mmol} \mathrm{L}^{-1}\end{array} \\
\text { Exp. }\end{array}$} & \multirow{2}{*}{$\begin{array}{c}C_{\mathrm{o}} \\
\mathrm{mmol} \mathrm{L}^{-1} \\
\text { Model }\end{array}$} & \multicolumn{2}{|c|}{$\begin{array}{c}\text { Stage } 1 \\
\text { Removal percentage, } \%\end{array}$} & \multicolumn{2}{|c|}{$\begin{array}{c}\text { Stage } 2 \\
\text { Removal percentage, } \%\end{array}$} & \multicolumn{2}{|c|}{$\begin{array}{c}\text { Stage } 1+2 \\
\text { Removal percentage, } \%\end{array}$} \\
\hline & & Exp. & Model & Exp. & Model & Exp. & Model \\
\hline 1.00 & 1.01 & 55.89 & 49.97 & 43.90 & 49.03 & 99.79 & 99.00 \\
\hline 2.00 & 2.02 & 47.68 & 51.27 & 51.42 & 47.73 & 99.01 & 99.00 \\
\hline 3.00 & 3.01 & 48.04 & 52.95 & 50.32 & 46.05 & 98.36 & 99.00 \\
\hline 4.00 & 4.04 & 52.48 & 53.99 & 45.93 & 45.01 & 98.41 & 99.00 \\
\hline 4.70 & 4.72 & 52.25 & 53.08 & 46.65 & 45.92 & 98.90 & 99.00 \\
\hline 1.00 & 1.01 & 55.51 & 49.97 & 42.48 & 52.52 & 97.99 & 95.00 \\
\hline 2.00 & 2.02 & 47.45 & 51.27 & 45.90 & 49.10 & 93.35 & 95.00 \\
\hline 3.00 & 3.01 & 48.64 & 51.36 & 46.55 & 48.45 & 95.19 & 95.00 \\
\hline 4.00 & 4.04 & 49.62 & 52.15 & 44.57 & 50.43 & 94.19 & 95.00 \\
\hline 4.70 & 4.72 & 50.80 & 51.81 & 44.15 & 43.19 & 94.95 & 95.00 \\
\hline 1.00 & 1.01 & 55.61 & 49.97 & 41.66 & 48.34 & 97.24 & 90.00 \\
\hline 2.00 & 2.02 & 50.80 & 47.24 & 40.55 & 49.45 & 91.35 & 90.00 \\
\hline 3.00 & 3.01 & 48.99 & 47.79 & 41.64 & 48.36 & 90.63 & 90.00 \\
\hline 4.00 & 4.04 & 49.55 & 49.99 & 41.10 & 48.90 & 90.65 & 90.00 \\
\hline 4.70 & 4.72 & 48.42 & 49.94 & 40.04 & 49.96 & 88.46 & 90.00 \\
\hline
\end{tabular}


Table 6 -Comparison of experimental and calculated values of removal efficiency obtained in stage 1 and stage 2 for different initial concentrations and removal percentages for cadmium

\begin{tabular}{|c|c|c|c|c|c|c|c|}
\hline \multirow{2}{*}{$\begin{array}{c}\begin{array}{c}C_{\mathrm{o}} \\
\mathrm{mmol} \mathrm{L}^{-1}\end{array} \\
\text { Exp. }\end{array}$} & \multirow{2}{*}{$\begin{array}{c}\begin{array}{c}C_{\mathrm{o}} \\
\mathrm{mmol} \mathrm{L}^{-1}\end{array} \\
\text { Model }\end{array}$} & \multicolumn{2}{|c|}{$\begin{array}{c}\text { Stage } 1 \\
\text { Removal percentage, } \%\end{array}$} & \multicolumn{2}{|c|}{$\begin{array}{c}\text { Stage } 2 \\
\text { Removal percentage, } \%\end{array}$} & \multicolumn{2}{|c|}{$\begin{array}{c}\text { Stage } 1+2 \\
\text { Removal percentage, } \%\end{array}$} \\
\hline & & Exp. & Model & Exp. & Model & Exp. & Model \\
\hline 1.00 & 1.01 & 55.89 & 49.97 & 43.90 & 49.03 & 99.79 & 99.00 \\
\hline 2.00 & 2.03 & 47.68 & 51.27 & 51.33 & 47.73 & 99.01 & 99.00 \\
\hline 3.00 & 3.04 & 48.04 & 52.95 & 50.32 & 46.05 & 98.36 & 99.00 \\
\hline 4.00 & 4.00 & 52.48 & 53.99 & 45.93 & 45.01 & 98.41 & 99.00 \\
\hline 5.00 & 4.99 & 52.25 & 53.08 & 46.65 & 45.92 & 98.90 & 99.00 \\
\hline 1.00 & 1.01 & 55.51 & 49.97 & 42.48 & 45.03 & 97.99 & 95.00 \\
\hline 2.00 & 2.03 & 47.45 & 51.27 & 45.9 & 43.73 & 93.35 & 95.00 \\
\hline 3.00 & 3.04 & 48.64 & 51.36 & 46.55 & 43.64 & 95.19 & 95.00 \\
\hline 4.00 & 4.00 & 49.62 & 52.15 & 44.57 & 42.85 & 94.19 & 95.00 \\
\hline 5.00 & 4.99 & 50.80 & 51.81 & 44.15 & 43.19 & 94.95 & 95.00 \\
\hline 1.00 & 1.01 & 55.61 & 49.97 & 41.63 & 40.03 & 97.24 & 90.00 \\
\hline 2.00 & 2.03 & 50.80 & 47.24 & 40.55 & 42.76 & 91.35 & 90.00 \\
\hline 3.00 & 3.04 & 48.99 & 47.79 & 41.64 & 42.21 & 90.63 & 90.00 \\
\hline 4.00 & 4.00 & 49.55 & 49.99 & 41.10 & 40.01 & 90.65 & 90.00 \\
\hline 5.00 & 4.99 & 48.42 & 49.94 & 40.04 & 40.06 & 88.46 & 90.00 \\
\hline
\end{tabular}

\section{Conclusion}

The design and optimization of a batch scale reactor is necessary to achieve better balance between capacity utilization and cost efficiency. The simple mass balance equation and the kinetic model of the Vermeulen's approximation have been used to develop a mathematical model for optimization of the number of sorption stages and the optimal minimum contact time in each stage to achieve the desired sorption efficiency for sorption of $\mathrm{Zn}$ and $\mathrm{Cd}$ on IMZ. The application and verification of the model has been confirmed by experiment. By using the model, it has been found that the application of the two-stage reactor is valid for the specific concentration range, up to $4.7 \mathrm{mmol} \mathrm{Zn} \mathrm{L}^{-1}$ and

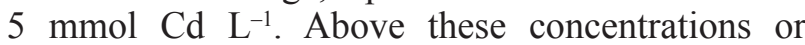
"pinch points", the application of three or more stages is needed. Thus, the initial concentration was found to be the key parameter affecting the sorption efficiency and the design of a two-stage sorption process. The application of the two-stage reactor reduces the contact time and enhances the sorption efficiency compared to the one-stage reactor for the same initial concentration.

\section{ACKNOWLEDGEMENT}

Preparation of this manuscript has been supported by the Croatian Science Foundation under the project HRZZ-NAZELLT IP-11-2013-4981.

\section{List of symbols}

$C_{\mathrm{o}} \quad$ - initial metal concentration, $\mathrm{mmol} \mathrm{L} \mathrm{L}^{-1}$

$C_{1}$ - metal concentration after stage $1, \mathrm{mmol} \mathrm{L}^{-1}$

$C_{2}$ - metal concentration after stage $2, \mathrm{mmol} \mathrm{L}^{-1}$

$C_{\mathrm{t}}-$ metal concentration at time $t, \mathrm{mmol} \mathrm{L}^{-1}$

$D_{\mathrm{i}} \quad$ - intraparticle diffusion coefficient of metal ions, $\mathrm{cm}^{2} \min ^{-1}$

$D_{\mathrm{i}, 1} \quad$ - intraparticle diffusion coefficient of metal ions in stage $1, \mathrm{~cm}^{2} \min ^{-1}$

$D_{\mathrm{i}, 2} \quad$ - intraparticle diffusion coefficient of metal ions in stage $2, \mathrm{~cm}^{2} \mathrm{~min}^{-1}$

$m$ - mass of sorbent, $\mathrm{g}$

$N \quad$ - stage number, -

$q_{\mathrm{o}}$ - solid-phase metal ions concentration initially, mmol g ${ }^{-1}$

$q_{\mathrm{e}} \quad$ solid-phase metal ions concentration at equilibrium, $\mathrm{mmol} \mathrm{g}^{-1}$

$q_{\mathrm{t}}$ - solid-phase metal ions concentration initially at time $t, \mathrm{mmol} \mathrm{g}^{-1}$

$q_{\mathrm{e}, \mathrm{exp}}$ - experimental solid-phase metal ions concentration at equilibrium, $\mathrm{mmol} \mathrm{g}^{-1}$

$q_{\mathrm{e}, 1}$ - solid-phase metal ions concentration in stage 1, mmol g ${ }^{-1}$

$q_{\mathrm{e}, 2}$ - solid-phase metal ions concentration in stage 2, mmol g ${ }^{-1}$

$r_{\mathrm{p}} \quad-$ particle radius, $\mathrm{cm}$

$R_{1} \quad$ - removal percentage in stage $1, \%$

$R_{2} \quad$ - removal percentage in stage $2, \%$ 
$R$ - overall removal percentage, $\%$

$t \quad$ - time, $\min$

$t_{1} \quad-$ minimum contact time in stage 1, min

$t_{2}-$ minimum contact time in stage 2 , min

$T-$ minimum total contact time, $\min$

$V \quad-$ volume of the solution, $\mathrm{L}$

\section{References}

1. Ho, Y. S., McKay, G., A multi-stage batch sorption design with experimental data, Adsorpt. Sci. Technol. 17 (1999) 233. doi: https://doi.org/10.1177/026361749901700401

2. Shukla, S. P., Singh, A., Dwivedi, L., Sharma, K. J., Bhargava, D. S., Shukla, R., Singh, N. B., Yapad, V. P., Markandeya, Minimization of contact time for two-stage batch adsorber design using second-order kinetic model for adsorption of methylene blue (MB) on used tea leaves, IJSIR 2 (2014) 58.

3. Markandeya, Singh, A., Shukla, S. P., Mohan, D., Singh, N. B., Bhargava, D. S., Shukla, R., Pandey, G., Yadav, V. P., Kisku, G. C., Adsorptive capacity of sawdust for the adsorption of MB dye and designing of two stage batch adsorber, Cogent Env. Sci. 1 (2015) 1.

4. Di Martino, M., Sannio, F., Pirozzi, D., Removal of pesticide from wastewater: contact time optimization for a twostage batch stirred adsorber, J. Environ. Chem. Eng. 3 (2015) 365.

5. Dyer, J. A., Trivedi, P., Sanders, S. J., Scrivner, N. C., Sparks, D. L., Treatment of zinc-contaminated water using a multistage ferrihydrite sorption system, J. Colloid Interface Sci. 270 (2004) 66.

doi: https://doi.org/10.1016/j.jcis.2003.08.022

6. Unuabonah, E. I., Adie, G. U., Onah, L, O., Adeyemi, O. $G$., Multistage optimization of the adsorption of methylene blue dye onto defatted Carica papaya seeds, Chem. Eng. J. 155 (2009) 567.

doi: https://doi.org/10.1016/j.cej.2009.07.012

7. Ho, Y. S., McKay, G., Batch sorber design using equilibrium and contact time data for the removal of lead, Water Air Soil Pollut. 124 (2000) 141. doi: https://doi.org/10.1023/A:1005218411809

8. Unuabonah, E. I., Adebowale, K. O., Ofomaja, A. E., Twostage batch adsorber design: a time-dependent Langmuir model for adsorption of $\mathrm{Pb}^{2+}$ and $\mathrm{Cd}^{2+}$ onto modified kaolinite clay, Water Air Soil Pollut. 200 (2009) 133.

9. Hui, C. W., Chen, B., McKay, G., Contact time optimization of two stage batch adsorber systems using the modified film-pore diffusion model, Chem. Eng. Sci. 57 (2002) 2863.

doi: https://doi.org/10.1016/S0009-2509(02)00144-6
10. Ho, Y. S., McKay, G., A two-stage batch sorption optimized design for dye removal to minimize contact time, Trans IChemE 76 (1998) 313. doi: https://doi.org/10.1205/095758298529678

11. Chen, B., Hui, C. W., McKay, G., Film-pore diffusion modelling and contact time optimization for the adsorption of dyestuffs on pith, Chem. Eng. J. 84 (2001) 74. doi: https://doi.org/10.1016/S1385-8947(01)00193-0

12. Bazargan, A., Shek, T.-H., Hui, C.-W., McKay, G., Optimising batch adsorbers for the removal of zinc from effluents using a sodium diimidoacetate ion exchange resin, Adsorption (2017). doi: https://doi.org/10.1007/s10450-016-9857-y.

13. Özacar, M., Şengil, I. A., A two stage batch adsorber design for methylene blue removal to minimize contact time, J. Environ. Manage. 80 (2006) 372. doi: https://doi.org/10.1016/j.jenvman.2005.10.004

14. Unuabonah, E. I., Olu-owolabi, B. I., Okoro, D., Adebowale, K. O., Comparison of two-stage sorption design models for the removal of lead ions by polyvinyl-modified kaolinite clay, J. Hazard. Mater. 171 (2009) 215. doi: https://doi.org/10.1016/j.jhazmat.2009.05.126

15. Ugrina, M., Vukojević Medvidović, N., Perić, J., Trgo, M., A study of kinetics and successive sorption/desorption of $\mathrm{Zn}$ and $\mathrm{Cd}$ uptake onto iron-modified zeolite, Clay Miner. 50 (2015) 117. doi: https://doi.org/10.1180/claymin.2015.050.1.11

16. Ugrina, M., Vukojević Medvidović, N., Daković, A., Characterization and environmental application of iron-modified zeolite from Zlatokop deposit, Desalin. Water Treat. 53 (2015) 3557. doi: https://doi.org/10.1080/19443994.2013.873743

17. Ugrina, M., Trgo, M., Vukojević Medvidović, N. Nuić, I., The effect of $\mathrm{pH}$ on efficiency of sorption/desorption of heavy metals on natural and iron-modified zeolite, Proceedings of the IWA 8th Eastern European Young Water Professionals Conference, Oficyna Wydawnicza Politechniki Wrocławskiej, Wrocław, 2016, 665-671.

18. Dyer, J. A., Trivedi, P., Sanders, S. J., Scrivner, N. C., Sparks, D. L., Lead sorption onto ferrihydrite, 3. Multistage contacting, Environ. Sci. Technol. 37 (2003) 923. doi: https://doi.org/10.1021/es0258551

19. Özacar, M., Contact time optimization of two-stage batch adsorber design using second-order kinetic model for the adsorption of phosphate onto alunite, J. Hazard. Mater. 137 (2006) 218. doi: https://doi.org/10.1016/j.jhazmat.2006.01.058

20. Pirozzi, D., Sannino, F., Design of a multi-stage stirred adsorber using meso-porous metal oxides for herbicide removal from wastewaters, J. Environ. Chem. Eng. 2 (2014) 211. doi: https://doi.org/10.1016/j.jece.2013.12.013

21. Helferich, F., Ion exchange, McGraw-Hill Inc., New York, 1962, pp. $250-322$ 